\title{
An Eclectic Method of College English Teaching
}

\author{
Wenjing Li \\ Zhejiang Gongshang University, Hangzhou, China \\ Email: lwjf@sohu.com
}

\begin{abstract}
The paper has taken a critical view of various approaches of language teaching, each of which may has its advantages and disadvantages. By analyzing these approaches and objectives of college English teaching, the writer tries to develop an eclectic method of language teaching strategy, which includes formal instruction and communicative activates. The respective role of teachers and students is also discussed in this paper.
\end{abstract}

Index Terms - college English teaching, communicative activities, role of students

\section{REVIEW}

In the long history of English teaching, people have tries various approaches to facilitate language learning. Before we design a new method, we have to take a critical view of these previous approaches.

\section{A. The Grammar-translation Method}

This method can be traced back to the study of Latin. It was the standard way of studying foreign language in the 19th century. As its name suggests, it focuses on the grammar learning with the principal technique of translation. It views language learning as grasping morphology and syntactic by memorizing rules. The goal is to appreciate literature. Speaking ability is relentlessly neglected. Though the class is easy to organize with this method, its usefulness is highly limited. Its major defect lies in no concern for students themselves. They are only passive path-followers. Besides Sentences are taught in isolation. Students cannot learn how to use sentences in communication. Additionally, vocabulary selection is based on reading texts instead of coverage and words are presented with translation equivalence so that interference of mother tongue cannot be avoided.

\section{B. The Direct Method}

From the latter part of the 19th century, many scholars made radical changes from Grammar-Translation Method. Parallel to the Reform Movement, interest was directed to the natural learning principles which provided foundation for Direct Method. Opposite to the Grammar-Translation Method it put emphasis on everyday spoken language instead of literary language. Its advocates argued that language could be taught through demonstration and action. So target language is the means of instruction and communication. Both speech and listening comprehension are taught. Correct pronunciation and grammar are emphasized. Grammar is taught inductively. According to H.H.Stern, it was "a first attempt to make the language learning situation one of language use and to train the learner to abandon the first language as the frame of reference"(Stern, 1983, p.459). However, it leads to much criticism because of its overemphasis on the similarities between first language acquisition and second language learning. Secondly, misunderstanding may arise because mother tongue is strictly forbidden. Lastly, it is not so realistic as it claims because it is too demanding for the teacher. Reading and writing abilities which many students need are neglected.

\section{The Oral Approach and Situational Language Teaching}

In the 1920s and 1930s, some British applied linguists including Harold Palmer and A.S. Hornby, developed an approach which was known as the Oral Approach. It is differentiated from the Direct Method in the aspect that it selects vocabulary and grammar systematically with gradation. Its key feature is that new language points are introduced and practiced in situations. Its theory of language is known as British "structuralism." Speech is regarded as the basis of language and structure is viewed as the heart of speaking ability. Material is taught orally before it is presented in written form. This theory regards language learning as habit formation. As a result, accuracy is considered crucial. However, in the boring process of repetition and substitution, students can never develop communicative strategy in real situations.

\section{The Audiolingual Method}

In the mid-fifties, Audiolingualism appeared on the basis of Army Specialized Training Program (ASTP) in America. Although in many aspects, it sounds similar to the Oral Approach, it differs in its alliance with American structural linguistics and contrastive analysis. Language is viewed as a system containing meaningful elements governed by certain rules. Behaviorism manifests itself in this approach. Language is regarded as verbal behavior and habit formation is considered crucial. Dialogues and drills are the basic elements of practice. Aural-oral training is provided before developing other skills. This approach leads to widely used courses such as English 900. When its theoretical 
foundations were attacked, this approach declined. Its failure can also be traced to "lack of effectiveness of the techniques in the long run" (Stern, 1983, p. 465). Basic patterns cannot ensure learners the ability to talk about different topics.

\section{E. Communicative Language Teaching (CLT)}

From the later 1960s, Situational Language Teaching began to be rejected. Later on, some new principles were rapidly accepted. They became known as the Communicative Approach of which there are many versions. All of them aim to "(a) make communicative competence the goal of language teaching and (b) develop procedures for the teaching of the four language skills that acknowledge the interdependence of language and communication." (Richards, 1986, p.66). It starts from a theory of language as communication. Classroom activities focus on meaningful tasks and information sharing. In these activities, students contribute a lot in a cooperative atmosphere. The teacher is the facilitator of the communication process and the participant of learning-teaching group. It is a great progress to include communicative and contextual elements into teaching since language is a tool for communication. Its classes are much more interesting. However, sometimes students have no sense of achievement. It is difficult for students with poor grammatical ability to develop ideal communicative competence. And the adoption of CLT requires the development of materials and evaluation systems.

\section{F. Total Physical Response (TPR)}

Proposed by James Asher, it takes a structuralist views of language. Verbs, especially imperative verbs are considered basic elements of language learning. It draws on three learning hypotheses. Firstly, Asher sees first and second learning almost the same. Speech evolves after listening comprehension has been established. Secondly, Asher claims language is learned through actions via right-brain. Lastly, it is one of humanistic approaches because Asher considers the absence of stress as key of successful language learning. Thus, at the beginning stage, students only have to do imperative drills. Speech is delayed until they are ready. Obviously, students can enjoy the classroom activities, which will facilitate learning. And from psychological point of view, combination with actions will increase the probability of successful recall. However, it can only be used for children at a beginning stage. We'd better associate it with other methods.

\section{G. The Silent Way}

In contrast to TPR, this method devised by Caleb Gattegno holds that the teacher should be as silent as possible while the students should produce as much language as possible. Its structural syllabus is just like some traditional method, but the way the classroom activity organized is innovative. Three factors, learners' process of discovery, accompaniment of physical objects and problem solving facilitate learning. Under Gattegno's hypotheses a teacher should present an item once and then direct students' response by silent means. Finally, the teacher should get out of the way during learners' interaction. Cuisenaire rods, pronunciation charts (Fidels) and word charts are used to help practice and recall. These means can stimulate memorization. Learners acquire sense of independence, autonomy and responsibility so that they will learn to learn by themselves, but I don't think total lack of feedback will produce ideal result. Besides, its content lacks communicative value.

\section{H. Community Language Learning (CLL)}

This method, which was developed by Charles A. Curran and his associates, is based on Counseling-learning theory. In recent versions, language is regarded as a social process in which feedback is emphasized. They also hold an interactional view of language. There are two kinds of interactions, those between learners and those between learners and knowers. The learner-knower relationship is compared to client-couselor relationship. The learners will undergo five stages of development: dependant, self-as-sertive, resentful, tolerant and independent. This process is parallel to the development of children. The students sit in circles and talk about any topics which interest them. The "knower" helps them with the language they want to use so that they can use the target language. The conversations are tape-recorded and transcribed to help them review. The teacher will elaborate on some grammatical points after discussion. Learners learn something when they need it so that it is easy for them to remember. It will keep the learners' motivation high by paying much attention to their communicative intent. Learners' emotions and feelings are highlighted. However, input is somewhat limited since there is difference between needs and wants. It may also lead to inadequate control of the grammatical system of the target language. Additionally, the evaluation becomes very difficult for lack of syllabus.

\section{The Natural Approach}

In 1983, Tracy Terrell and Stephen Krashen published The Natural approach, which attracted a lot of interest. The term natural means the principles similar to those of naturalistic language learning in young children. They maintain that language's main function is communication and lexicon is critical in language. According to Krashen's language acquisition theory, acquisition is unconscious while learning is conscious. Comprehensible input (the input that is slightly beyond learners' level) should be presented as much as possible before speech ability "emerges". Furthermore, a low affective filter will facilitate learning. To achieve this goal, it is up to the learners when to speak and what to speak about. In the pre-production stage, students are exposed to the target language without responding in that language. In the early-production stage, students respond with single words. And in the speech-emergent phase, students 
involve in communicative activities. This approach has the advantage of communicative method and humanistic method. There is still a problem, however, on how the fluent speech will necessarily emerge after the acquirer has received enough input.

\section{J. Suggestopedia}

This method is developed by the Bulgarian psychiatrist-educator Georgi Lozanov. It has borrowed from yoga and Soviet psychology. According to him, most learning takes place in a relaxed but focused state known as "pseudo-passive state". Suggestion is at the heart of Suggestopedia. Learners return to the state of infant while the teacher serves as authority. Learners thus regain self-condidence. Learning environment is considered so important that classroom is decorated as bright and cherry and reclining chairs are arranged in a circle. The use of music is one of its conspicuous features. The teacher gives proper dramatic readings with a musical background. Its syllabus contains mainly dialogues. The texts are selected to cater for learners' emotional needs. New material is presented with its translation. The students follow the pattern of fixation, reproduction and new creative production. They are also asked to memorize a long list of vocabulary. Although this method has received much criticism, we can still borrow something for our purpose. For example, the original idea of using music in reading can benefit learners a lot.

\section{OBJECTIVE}

With the increasing development of economy, people throughout the world get in touch with each other more frequently than ever. As a result, leaning foreign language has become more and more important, especially English which is almost the international language. In China, English is one of the major subjects for college students. As the College English Syllabus requires: "College English aims to develop in students a relatively high level of competence in reading, an intermediate level of competence in listening and a basic competence in writing and speaking. After completion of the course, the students should be able to use the English they have learned as a means to obtain whatever information they need in their field of specialization and also a solid foundation for further improvement of their command of the language" (1986, p.1-2).

That is to say, a successful learner can use English as a way of communication and they can also make further improvement independently. Many Chinese learners have learned many grammatical rules, but it is difficult for them to communicate with appropriate sentences in real situations. From CET-6, we can see that they do not do well in writing. It suggests they lack an ability to produce coherent discourse. In a word, they need to increase their communicative competence urgently.

\section{THEORY OF LANGUAGE AND THEORY OF LEARNING}

There is no single method which could guarantee successful results. We have to take an eclectic view in the previous methods according to learners' needs and objectives. Before we design concrete techniques, we should make it clear what language is and what factors facilitate learning.

\section{A. Theory of Language}

The advocates of communicative approach maintain the theory of language as communication. They have discussed the communicative competence from many aspects. A recent version is held by Canale and Swain (Richards, 1986,p.71) As they claim, there are four dimensions of communicative competence: grammatical competence, socio-linguistic competence, discourse competence and strategic competence. Grammatical competence means grammatical and lexical capacity. As to socio-communicative competence, it refers to the social context of communication. Discourse competence focuses on the interconnectedness of individual message. Strategic competence refers to the strategies in communication, such as strategies to initiate or terminate communication.

This analysis represents the communicative view of language. In fact, language is one way of communication. Structures which are components of language serve to perform various functions in social context.

\section{B. Theory of Learning}

Firstly, let's see the relation between input and output. According to Krashen's Natural Order Hypothesis, people acquire language most effectively by receiving sufficient I+1 input which is slightly beyond their current level. After sufficient input has been provided, learners can speak fluently. Great importance is attached to input. It is just like first language acquisition. Without enough input of natural target language, it will be difficult for learners to produce native-like speech. However, input itself is not enough. Krashen fails to explain convincingly how input can be automatically transferred into output. In fact, if the learner never speaks target language, he will never reach speech fluency. For example, many Chinese students who are good comprehenders speak broken English. Swain proposed the Comprehensible Output Hypothesis. She argued that we have to actually speak in order to learn.

By speaking the target language frequently, learners can also identify their limitations. When they put their knowledge into use, they will recognize what they don't know and then they can fulfil the gap afterwards. In this way, they can improve step by step.

Output and input are complementary. Peter Skehan discusses six roles of output $(1998, \mathrm{p} 16)$ : 1) To generate better 
input. 2 ) To force syntactic processing 3 ) To test hypothesis 4) To develop automacity5) To develop discourse skills 6) To develop a personal voice

From these six roles, we can see that output and input are closely related. In interaction, one gives feedback to his counterpart so that he can get input more finely tuned. From the input, the learner can also learn how to express meanings. Additionally, the learner can draw revealing information for his language hypotheses from feedback. In this sense, learning is best facilitated if the learner receives sufficient input and generates enough output. In class, the teacher should make a balance between input and output. Traditional class is full of teacher's instruction. Input is over-emphasized. The learner has no opportunity to speak the target language. Its drawback is obvious. In an ideal class, the teacher gives sufficient input and at the same time provides the students opportunities of meaningful communication.

Secondly, I quite agree with the humanistic approach which engages the whole person. Learners should be treated as individuals. Their emotions and feelings will affect learning process. Sometimes, affective factors even contribute mote than the cognitive factors. As Krashen points out, learners with a low affective filter receives more input. According to him, three kinds of affective variables are related to second language acquisition: motivation, self-confidence and anxiety. Many investigations have proven that there is a positive association between learning effect and motivation in learning. Harmer (1991) distinguishes two kinds of motivation: extrinsic motivation and intristic motivation. It has great pedagogic implication. What a teacher can do is to help learners highly motivated by making learners attracted by the target culture, making teaching process attractive or giving learners sense of achievement, etc. If the learner really wants to learn, he will succeed more easily. Besides motivation, self-confidence and anxiety also affect learning outcome. Some learners often complain when they are relaxed, they can do much better what they cannot do in examination. In fact, during the examination, the affective filter is high. If the learner does listening comprehension at that time, the information he processes is much less than the input. It suggests that the teacher should create a supportive environment to help the learner lower the affective filter. However, the absence of stress also has the negative effect. Many learners have the experience that they memorize well before the examination. They are afraid of failure in examination. In this case, they try their best to learn. Consequently, learners with proper stress can achieve best results.

Lastly, learning styles and learning strategies will influence the learning rate. The main categorization of learning style is the concept of field dependence/independence. Field independence learners are more likely to separate the whole into its components and analyze them independently. Field dependant learners tend to perceive problems as wholes. They are more sociable. (Skehan, 1998) There are some alternative views of styles. Peter Skehan points out neither pole of the style dimension is regarded as being as 'better' but instead is simply seem to suggest alternatives. Further, each pole is seen as having advantages for different tasks. Thus, it is rewarding for learners to know about their own style and try the alternatives in different tasks. It will also be helpful if the learner knows something about good learning strategies and apply them in their learning. For example, Brown and Perry (1991) conducted an investigation of three vocabulary-learning strategies: keyword (forming a visual association between the target word and some acoustically similar word), semantic (integrate the target word into the learner's existing semantic system), and keyword-semantic (combination of the first two). It proved that the third strategy resulted in the best retention. Some learners only learn words by rote. If they use the previous memorization strategy for reference, they can get higher recall rate. So if language learners are aware of their learning strategies and make use of other good ones, their leaning will be more effective.

\section{ACTIVITIES}

In class, there should be a rich mixture of activities, which mainly includes formal instruction and communicative tasks. The content and form of these two categories should also be versatile. There are several reasons. First of all, grammatical competence is a component of communicative competence. Widdowson (1978, p144) believes "the teaching of language as communication calls for an approach which brings linguistic skills and communicative abilities into close association with each other." Although college students have learned much about grammatical system of English, some of them still get confused by some basic grammatical concepts. Secondly, it is for the benefit of all the students. Different students have different learning styles and preferences. Some prefer formal instruction while some enjoy communicative activities. If the teacher pays no attention to their respective need, they will feel insecure and have no sense of achievement. A variety of activities will cater for the interest of all the students and be suitable for mixed ability groups. During these activities, learners will also notice different learning strategies and make improvement. Lastly, monotonous activities can never keep the students highly motivated. Only various activities can catch their attention.

\section{A. Formal Instruction}

Traditionally, the role of the teacher is the sole instructor who analyzes texts and grammar. This method should be abandoned. However, appropriate elaboration of vocabulary and grammar should be reserved. Before students read a text or do listening comprehension, some knowledge of key words will lead to effective result. Sometimes, difficult syntactic structure of certain sentences will prevent the students understanding the whole text. In this case, the teacher's 
explanation is necessary. It will help the students become conscious of such structures so that they will not find it difficult next time. Some students' grammatical competence is far from adequate. It is necessary for the teacher to fill the gap. However, this kind of formal instruction should not take up most of a class. The way of teaching vocabulary and grammar is various. Take vocabulary teaching as an example. As Harmer (1991) asserts, for learners at intermediate levels, we'd better ask the students to discover what a word means and how it is used. Thus, for college students, explanation and translation should not be always used. The teacher can present new words in a story or real situations, especially those related to the students' lives, so that students will learn the meaning in context. Pictures and actions will also help the students discover the meaning. Additionally, new words can be presented with other similar words so as to make its meaning clear. As to grammar, we'd better explain it in a discourse so that its communicative value is stressed. Rather than know about rigid syntactic rules learners can use appropriate structures in various types of discourse.

\section{B. Communicative Activities}

Communicative activities are the main part of a class. There are all kinds of such activities. For instance: role play, problem solving, debate, group discussion and etc. Written communicative activities such as writing reports should also be included. There are three points we should pay munch attention to.

First of all, a balance between input and output is recommended. The rationale has been discussed before. In practice, we can integrate more than one macroskill. For example, after listening to several pieces of news from VOA, we can ask students to write a comment on the news. Their specific content and form should cater for the learners' communicative intent. The topics should include what the learners' need and what they want. For example, the topics interest the college student are strongly recommended, such as environment protection, Internet and cultural difference. For students of different specialties, relevant information can be provided to help them deal with English material of their field of specialization. As the facilities of universities are much better than before, we can make use of these modern means such as videotapes and films. Traditional or popular English songs can increase the learners' interest as well as develop their listening comprehension. Articles selected from Internet can also serve as complementary reading material. Additionally, teacher can encourage the learner to read English novels and newspapers after class because input from class is far from sufficient.

Secondly, the teacher should refrain from too much error correction. Even if the learner makes great mistakes, the correction should be provided after he finishes his contribution. Otherwise, it will be difficult for them to develop fluency. The responsibility of error correction can be assumed by the students themselves rather than the teacher so that they will learn from mistakes. For example, after the students write a report, they are asked to form a group. Each group member reads all the reports of this group. Then, they discuss whether there are grammatical mistakes, inappropriate sentence for the style, or incoherence in the discourse. They will develop independence in this process.

Thirdly, it is important to learn how to learn. Students will be sensitive to the learning process if they are encouraged to reflect on their learning styles or talk about their learning strategies. Opportunities should be provided to plan their own learning. Simultaneously, the teacher gives some directions in learning strategies. In this way, learners can continue learn foreign language effectively after the course is over.

\section{LEARNER Roles AND TEACHER ROLES}

Learners are the center of the class. They have multiple roles. As individual, they are active participants of the activity, explorer of the language, negotiator and evaluator of the learning process. Their needs and interests influence the course. As a group member, the learner is the source of the input and part of a support system. Students work co-operatively in classroom activities. Their output is the others' input. They help each other in solving problems rather than depending wholly on the teacher. We can use group discussion in solving the problems so as to encourage independence. In a word, the learner takes initiative in the classroom.

The teacher is the guide of the learning process. Krashen and Terrel consider it important to tell the learners what they should and should not expect of a course. At the very beginning, the learner can have a specific goal. The role of guide also lies in giving advice for learning strategies. During the communicative activities, the teacher is both the organizer and the resource. When the activity is finished, the teacher gives appropriate feedback which focuses on the content of the activity. Communication of meaning is primary. When the use of English is discussed, emphasis should be laid on the appropriateness according to different roles the learner plays instead of grammatical mistakes. Additionally, it is important for the teacher to create a warm atmosphere in classroom so that a positive attitude on learning English is easy to develop.

\section{CONCLUSION}

All the previous approaches have something we can make use of. I try to develop a way appropriate to Chinese college students. However, the specific procedures and activities should depend on the specific learners. Different groups of learners at different time call for different treatment. Continuing research is needed as the course progresses. 
[1] College English Syllabus Revision Team. (1986). College English Syllabus (For Students of Arts and Science). Shanghai: Shanghai Foreign Language Education Press.

[2] Ellis, Rod. (1985). Understanding Second Language Acquisition. Oxford: Oxford University Press.

[3] Ellis, Rod. (1994). The Study of Second Language Acquisition. Oxford: Oxford University Press.

[4] Harmer, J. (1991). The Practice of English Language Teaching. London: Longman.

[5] Liu Runqing. (1999). On College Language Teaching. Beijing: Foreign Language Teaching and Research Press.

[6] Richards, Jack C. and Theodore S. Rodgers. (1986). Approaches and Methods in Language Teaching. Cambridge: syndicate Press.

[7] Skehan, Peter. (1998). A Cognitive Approach to Language Learning. Oxford: Oxford University Press.

[8] Stern, H.H. (1983). Fundamental Concepts of Language Teaching. Oxford: Oxford University Press.

[9] Widdowson, H.G. (1978). Teaching Language As Communication. Oxford: Oxford University Press.

Wenjing Li holds a MA degree in applied linguistics from Zhejiang University in China. Her research interest lies in linguistics and investigation of language teaching strategies. She is now teaching in Zhejiang Gongshang University. She has recently published in Journal of Culture \& International Languages. 